\title{
Using an osmotic membrane pressure actuator (OMPA) for enhanced oil and gas recovery - the concept
}

\begin{abstract}
The concept by using an osmotic membrane pressure actuator (OMPA) to shut down a water producing branch of an oil or gas well is being investigated and has been described in the current article. The OMPA valve can be installed in a side-branch of the main well pipeline, where oil flows on the feed side of the membrane and a concentrated salt solution is kept in a chamber on the other side (draw side). Any water present in the oil will induce water permeation through the membrane in to the draw solution. This will cause a pressure increase on the permeate (draw) side and trigger the valve to shut down the water producing branch of the pipeline. There are several material challenges for the membrane when operating under harsh well conditions - some of which are discussed in this work. As a reference, a commercial forward osmosis (FO) membrane was tested in both FO and pressure retarded (PRO) process conditions for studying the relationship between membrane water flux and response time, and the influence of the oil/water feed flow rates. These experiments were used as a base case. A suitable membrane water flux from these data was predicted to be in the range of 0.08 to $0.3 \mathrm{~L} /\left(\mathrm{m}^{2}\right) \mathrm{hr}$ at the given well conditions $\left(180 \mathrm{bar}, 165^{\circ} \mathrm{C}\right)$, given the response time for closing off the water producing branch was around one week. Two other membrane materials with properties more suitable to withstand the expected harsh well conditions were chosen for further investigations - some experimental results are reported here. These materials are polybenzimidazole (PBI) doped with $\mathrm{LiCl}$, and a proprietary fluoropolymer. (The development of the fluoropolymer is still ongoing and will be reported separately.) Further, in order to choose the best suited salt for the draw solution in the permeate chamber of OMPA, the osmotic pressure of three salts were investigated by using the simulation tool OLI Analyzer. From this investigation, it could be concluded that the drawing salt solution to be used in OMPA should be chosen from salts with low osmotic pressure, such as a mixture of $\mathrm{Na}_{2} \mathrm{SO}_{4}$ with $\mathrm{NaCl}$. In lab, however, where operating conditions are much lower pressures and temperatures, it is useful to choose a salt like $\mathrm{MgCl}_{2}$ which will produce a high osmotic pressure also at these experimental lab conditions $-\mathrm{MgCL}_{2}$ was thus chosen for the bench-scale experiments reported here to mimic osmotic pressure at well conditions. From the experimental results and the simulation results from the OLI Analyzer, a response time for the OMPA valve could be estimated. If successfully designed, the OMPA valve has a great potential for enhanced oil and gas recovery (EOR, EGR) by shutting off water producing branches while the main part of the oil/condensate well continues to produce.
\end{abstract}

Keywords: Osmotic membrane, osmotic pressure, membrane materials, pressure actuator, draw solution.
Volume 3 Issue 2 - 2018

\author{
Qiang Yu, Maria Teresa Guzman Gutierrez, \\ May-Britt Hägg \\ Department of Chemical Engineering, Norwegian University of \\ Science and Technology, Norway
}

Correspondence: May-Britt Häg, Department of Chemical Engineering, Norwegian University of Science and Technology, Norway, Tel +47 73594033, Email may-britt.hagg@ntnu.no

Received: February 13, 2018 | Published: March 19, 2018

\section{Introduction}

The energy demand in our modern society is continuously rising, which clearly shows that fossil fuels will for many decades still play an important role - oil and natural gas are important energy resources in this picture. Nevertheless, oil and natural gas reserves are limited, and it is therefore a prioritized task to produce more oil and gas from existing wells and reservoirs for better exploitation of the resources. One of the challenges in the exploitation of gas and oil wells is often the heterogeneity of the reservoir, which increases the probability of water production, (i.e. increased water content in the hydrocarbon stream) originating from formation water or injected water. Produced water may cause unstable and reduced production rate which in turn gives a reduced gas and oil recovery. Technology developments over the past decades have made it possible to drill sophisticated wells for increased reservoir exposure and increased recovery. This includes long horizontal sections and multi-branched wells which have been the most important steps towards better utilization of the reservoir due to higher rate of return than for conventional wells, lower production costs and reduced number of platforms and wells per field. ${ }^{1,2}$ Handling of produced water is a major challenge in oil and gas production. Global produced water production of onshore and offshore was in 2009 estimated at about 250 million barrels per day, while produced oil was around 80 million barrels per day. ${ }^{3}$ Produced water is considered the largest volumetric waste stream in the oil and gas production processes. Produced water contains some organic hydrocarbons and 
various salts, and also inorganic components which may be toxic to the surroundings. ${ }^{4-6}$ Therefore, many countries have strict regulations for water discharge. ${ }^{7,8}$ The treatment of produced water is difficult and expensive in order to meet the environmental requirement. ${ }^{9,10}$ Especially on an off-shore platform, the separation and treatment of produced water requires extra processing facilities which are adding weight and space requirements. In addition the large volume produced water is a burden for the loading of transport equipment.

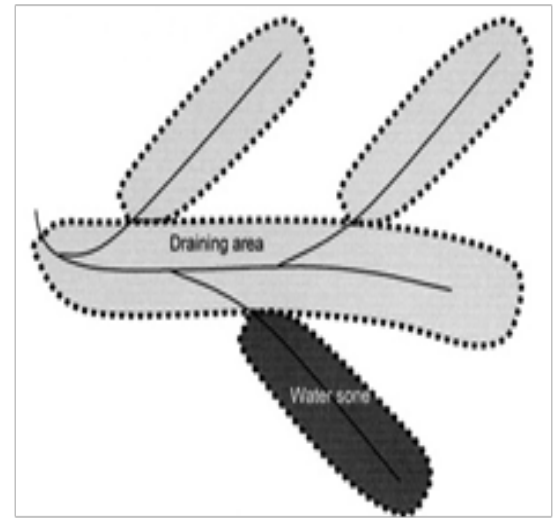

Figure I Sketch of branched well.

The produced water may originate from layers both above and below the hydrocarbon zone. In the initial period of oil and gas production in a new field, the oil/gas flow into well pipes by natural pressure depletion. Produced water may come from formation water flowing with the oil in the oil bearing formation, from water intrusion from an underlying water zone, or from breakthrough of water injected for pressure maintenance and oil displacement. The produced water along with oil/gas is thus transported to the topside. A method has been developed for detecting from where in the well the produced water is coming The method can estimate inflow locations with production flow by the utilization of tracer material, ${ }^{11-13}$ and can thus provide significant information of fluids influx and locations for process operation decision. The method can, however, not trigger a shut-down of the branch where the unwanted produced water is entering the local well pipes. Large volume of produced water in oil/ gas reduces the oil/gas recovery increases the separation and cleaning cost. When more water is produced, the cost of treatment will at some point become more than the profit of oil/gas production, and the well has to be kept shut even though there may still be large volumes of oil/gas left in some layers of the reservoir. Currently, many wells are branched, and the operation of these wells is expensive when waterbreaks through (Figure 1).

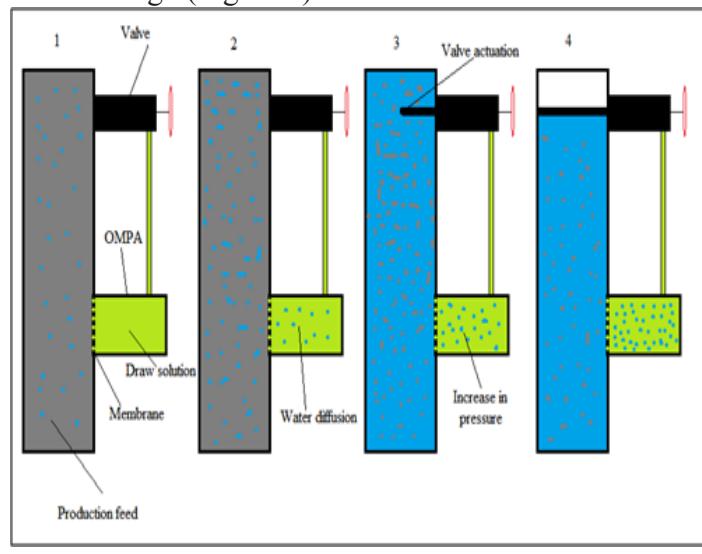

Figure 2 Schematic design of OMPA.
The OMPA valve is planned to be installed in the reservoir sections of the production tubing to shut off water producing branches automatically, (Figure 2) (Figure 3). In heterogeneous reservoirs, OMPA can thus shut off the water producing sections, while oil/ gas can still be produced from other zones. The OMPA valve should thus also reduce problems such as corrosion, cost of separation and cleaning. The objective of the work is thus to investigate various challenges related to the design of an OMPA valve which may be installed in a well to shut down a water producing branch while other parts of the well continues to produce oil/condensate. This is the core idea behind the osmotic membrane pressure actuator (OMPA). The many challenges related to the design of this OMPA are discussed in sections 3 and 4. This relates also to the choice of draw solution (salts) in the osmotic chamber, as well as the development of a good membrane material which can withstand the harsh conditions in a high pressure / high temperature well. The various challenges are investigated and reported in the current paper.

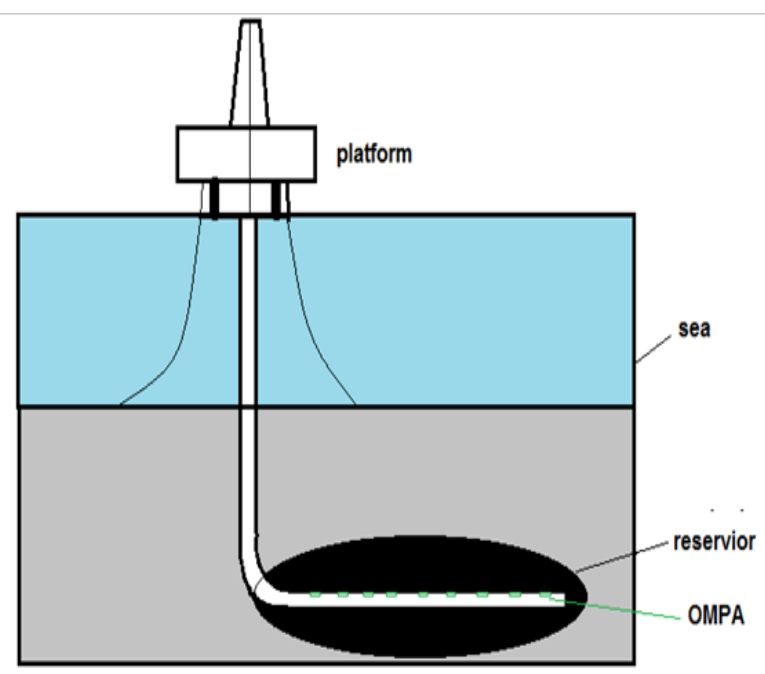

Figure 3 OMPA in local joints.

\section{The principle of the osmotic membrane pressure actuator}

The key-part of OMPA is an osmotic membrane. The principle of OMPA is based on a pressure retarded osmosis (PRO) process where the produced water/oil/condensate is the feed stream flowing passed the osmotic membrane in the actuator, while on the permeate side of the membrane there is a chamber containing a draw solution, for example a saturated salt solution, such as magnesium chloride or sodium chloride. Water will permeate through the osmotic membrane and enter into the chamber of draw solution. This will cause the pressure in the chamber to build up and to ultimately reach a prechosen set pressure to trigger a control valve. The triggering of this control valve should then result in closing off the water producing branch. The concept of the OMPA device was patented by Statoil (previously Norse Hydro). ${ }^{14}$ A schematic design is shown in Figure 2. OMPA may be installed on the wall of a drainage pipe (Figure 3). When there is no water produced, oil will flow freely passed the OMPA to drainage pipes, while the shutting down plate is in an open position. When water is permeating through the osmotic membrane and the pressure is starting to build-up in the cell (as indicated in Figure 2) the shutting down plate will gradually move to close the pipe for the fluid passing. Because reverse salt flux may occur, a salt box reservoir is designed to compensate the loss of salt. The choice of membrane material is 
naturally crucial to minimize a reverse salt flux. This has also been investigated and is reported in the current project.

\section{Osmotic membrane theory}

\section{General}

The theory on osmotic membranes can be found in many textbooks - the basics here can be referred to M. Mulder. ${ }^{15}$ Likewise, descriptions and reviews of various osmotic processes are nicely presented by several authors, here is only referred to. ${ }^{16-20}$

An osmotic membrane is a semi-permeable membrane where water is transported from a solution of higher water chemical potential (dilute solution) to a solution of lower water chemical potential (concentrated solution). An ideal osmotic membrane allows the permeation of solvent (usually water) but rejects the passage of solute (usually salts). According to the direction of external applied pressure, the osmotic process without any external applied pressure is recognized as forward osmosis (FO), while for reverse osmosis (RO) there will be an external applied pressure. Forward osmosis (FO) utilizes the osmotic pressure differential $(\Delta \pi)$ as driving force for transport of water through the membrane. The water flux flows across the membrane from the dilute solution to more concentrated solution (draw solution). Reverse osmosis (RO) uses hydraulic pressure differential as driving force for transport of water from concentrated solution to dilute solution. Pressure retard osmosis (PRO) can be regarded as an intermediate process between FO and RO. Hydraulic pressure is applied on the side of the concentrated solution, opposing the direction of osmotic pressure, however, the net water flux will still flow from dilute solution to concentrated solution. The processes of FO, PRO and RO are illustrated schematically in Figure 4. ${ }^{15,16}$ The water flux across an osmotic membrane can be described as in equation 1 . This theoretical equation does not take into account that there most likely will be some fouling and concentration polarization in the system - in a real case, the water permeability is apt to change. This is however, not taken into consideration in the reported experiments here. as the experiments are referred to as base case.

$$
J_{w}=A(\Delta \pi-\Delta P) \ldots \ldots \ldots \text { (Eq. 1) }
$$

Where $J$ is water flux $\left[\mathrm{m}^{2} / \mathrm{m}^{3} \mathrm{~s}\right]$, A is the water permeability constant $\left[\mathrm{m}^{3} / \mathrm{m}^{2} \mathrm{~s}\right.$ bar] (also define as the hydrodynamic permeability coefficient) of the membrane, $\Delta \pi$ [bar] is the osmotic pressure difference, and $\Delta P[\mathrm{bar}]$ is the applied pressure.

For FO, $\Delta P=0$; for PRO, $\Delta P<\Delta \pi$; For RO, $\Delta P>\Delta \pi$.

Osmotic pressure can be expressed as in equation 2 ,

$$
\pi=-\frac{R T}{V_{i}} \ln a i
$$

Where $\pi$ is the osmotic pressure of solution, $R[\mathrm{~J} / \mathrm{mole} \mathrm{K}]$ is gas constant, $\mathrm{T}[\mathrm{K}]$ is the temperature of solution, $V_{\mathrm{i}}\left[\mathrm{m}^{3} / \mathrm{mole}\right]$ is the molar volume, $a_{\mathrm{i}}$ is the water activity of solution.

The water activity of pure water is 1 , thus the osmotic pressure of pure water is 0 . If distilled water is used as feed solution in a FO process or PRO process, the osmotic pressure difference $\Delta \pi$ approximately equates to the osmotic pressure of the draw solution. Bear in mind that there will be a decline over time in the osmotic pressure caused by the dilution of the draw solution by water permeating into the chamber.

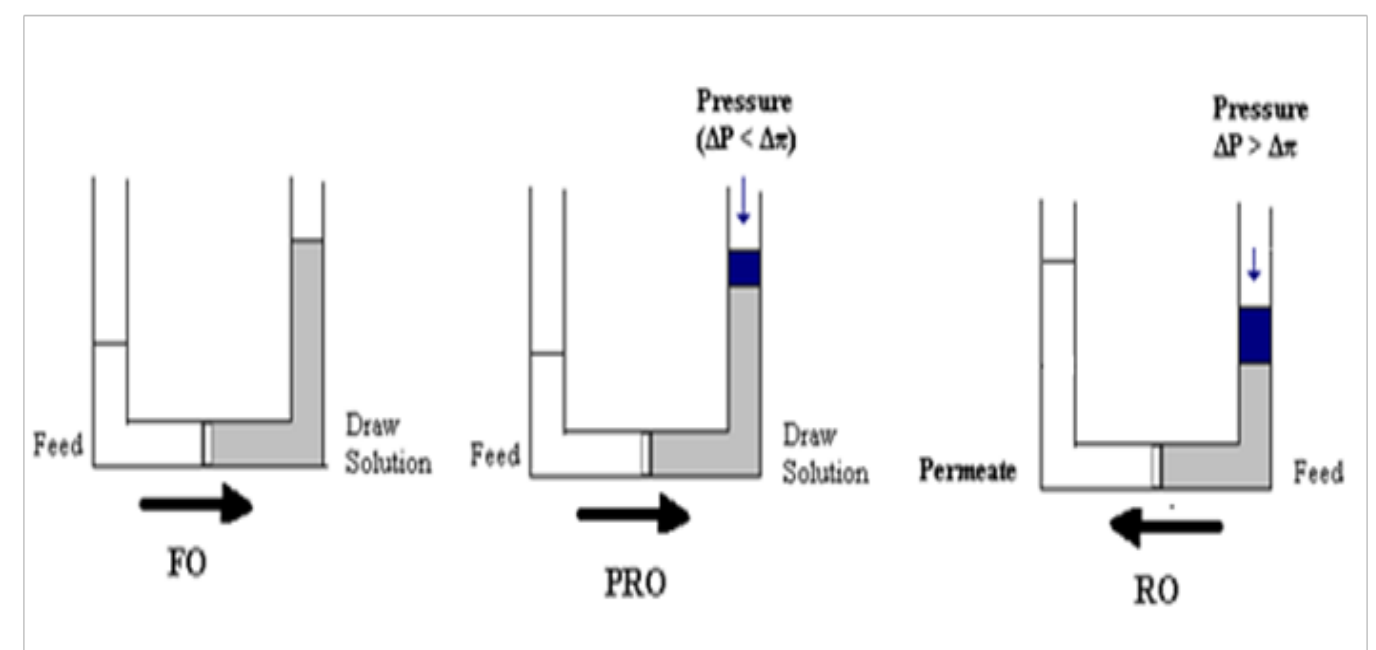

Figure 4 Schematic illustration of osmotic processes: FO, PRO, RO.

Likewise, a salt flux may be established from the concentrated solution to the dilute side across the osmotic membrane when the membrane is not perfectly semi permeable. The reverse salt transport can decrease the concentration difference between the two sides of the membrane resulting in a reduction of the effective osmotic pressure difference. The salt permeability coefficient $(B)$ of an osmotic membrane can be described as in equation3. In the current investigations, the revers salt flux is an important parameter to minimize by choice of the most suitable membrane material.

$$
B=\frac{A\left(1-R_{j}\right)(\Delta \pi-\Delta P)}{2}
$$

Where $\mathrm{R}_{\mathrm{j}}$ is salt rejection, defined as:

$$
R_{j}=1-\frac{C P}{C F}
$$

Where $C_{P}$ is the salt concentration in the permeate solution and $C_{F}$ is the salt concentration in the feed solution. 


\section{Challenges and desired properties of an osmotic membrane for OMPA}

As already mentioned, the heart of the OMPA valve is the membrane material, and it is hence crucial that the properties of the material are designed for the harsh well conditions (high pressures and temperatures), separation properties, and correct thickness. The osmotic membrane for OMPA adopts the principle of a PRO process so that the osmotic pressure which will build up on the draw solution side, will counteract the high pressure on the reservoir side. Further, this pressure increase will act on an actuator which will close the valve at a prechosen set pressure. The OMPA should not respond to small amounts and or discontinuous water production in oil/gas, but respond to large amounts of continuous water. Thus, a membrane with low water permeability constant (A) is preferred. Moreover, to reduce the long term loss of salt, a membrane with low salt permeance is needed, since there will probably be no way to add more salts to the draw solution reservoir of OMPA when it is installed deep down in a well. This is the reason for including a salt box (not shown in Figure 2). The draw solution will be in direct contact with this salt reservoir and should stay saturated. As the produced water also will contain a lot of salts, the type and concentration of these must be taken into account when draw solution is chosen. This is the background for the investigations performed on salt solutions in the current project and referred in section 4 . Information on salt content in the produced water is easily obtained from the oil/gas producer.

There are several ways to adjust the response time, and a few are mentioned here: Thickness of membrane, adjusting the permeability of the material in the preparation procedure, choosing the right draw solution and adjusting the membrane area compared to the volume of the draw reservoir. The most important is of course the durability of the membrane material over time. The conditions in a well where water is produced can be quite harsh; such as particles (sand), acids (from washing), higher hydrocarbons, $\mathrm{H}_{2} \mathrm{~S}$, etc. All these factors were considered when deciding on the membrane materials investigated and reported here.

The most severe problem known to reduce the effective osmotic pressure difference across the membrane is concentration polarization. Concentration polarization indicates that the solute concentration is different at both membrane surfaces and from that in the bulk. In PRO process, the selective dense layer of the membrane faces the draw solution and the porous support layer faces the feed solution. Both external concentration polarization (ECP) and internal concentration polarization (ICP) can take place in a PRO system. Concentration polarization occurs on the dense layer externally and in the porous support layer internally, which is illustrated in Figure 5. ${ }^{21}$ Concentration polarization is, however, not investigated or reported in the current article.

Usually RO and FO membranes are asymmetric membranes with a thin selective layer, which provides high water flux. For the OMPA membrane, the response time is a more important variable than high water flux. In the current project, two types of membrane materials are thus being investigated. Both membranes have symmetric configuration. For a thicker membrane different type of support can be used. This is judged to be more attractive, as the internal concentration polarization thus will be reduced. Considering the sealing of the membrane in OMPA, it is foreseen that hollow fibers might be difficult to seal properly with the metallic parts under high temperature and high pressure as well as high salt concentration, while a flat-sheet membrane can be easily sealed with thermally and chemically resistant Teflon or metallic O-rings or gaskets. A flat sheet membrane configuration was thus investigated.

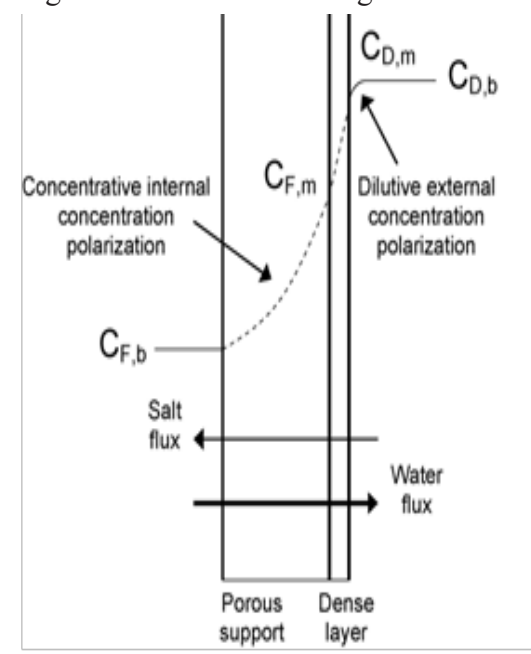

\section{Figure 5 Illustration of concentration polarization in PRO mode.2I}

Membrane fouling may be more difficult to control in such a system. It is defined as the (ir) reversible deposition of retained particles, emulsions, suspensions, macromolecules, salt etc. on or in the membrane, including surface fouling and fouling in pores. ${ }^{15}$ In the fouled membrane, a decline in flux is often observed. For OMPA, fouling may take place on the membrane surface or porous support caused by deposition of emulsions and organic precipitates from the crude oil. It is therefore of great importance to know the composition of the fluid in the reservoir, and optimize the flow across the membrane to avoid deposition. The chemicals used in cleaning of pipelines should also be considered for a potential effect on the OMPA membrane material.

\section{Investigation of materials and methods for OMPA}

Design criteria for the OMPA-valve will be based on well conditions of a given field. The operating pressure is high $(\rightarrow 200$ bar) and likewise temperature $\left(\rightarrow 200^{\circ} \mathrm{C}\right)$. As mentioned, an acid is often used as cleaning agent in production wells - this is taken into account when choosing the material. Prescreening of some materials were done, PBI and a specific fluoropolymer were found to be suitable and are currently under development for optimized performance with respect to water flux and reverse salt flux s. As a first step and for being used as a reference case, experiments were run using a commercial flat sheet cellulose triacetate (CTA) membrane provided by Hydration Technology Innovations (HTI) (Albany, OR, USA). These experiments helped to point out the direction of how to design the specific membrane material for OMPA. The simulation tool OLI Analyzer was further used to guide on which salts might be suitable for draw solution (reported in section 4.1).

\section{Selection of salt for the draw solution in OMPA}

The osmotic pressure build-up will strongly influence the design of the actuator, and for which pressure the valve should close. 
The osmotic pressure of various salts at different pressures and temperatures was thus calculated by the program OLI Analyzer, in order to recommend the right salt solution (draw solution) to be used for OMPA when installed in the well, and for selecting a suitable salt for bench scale experiments to mimic the well conditions. The traditional method for calculation of osmotic pressure is implemented in the software as illustrated in equation $2 .^{22}$

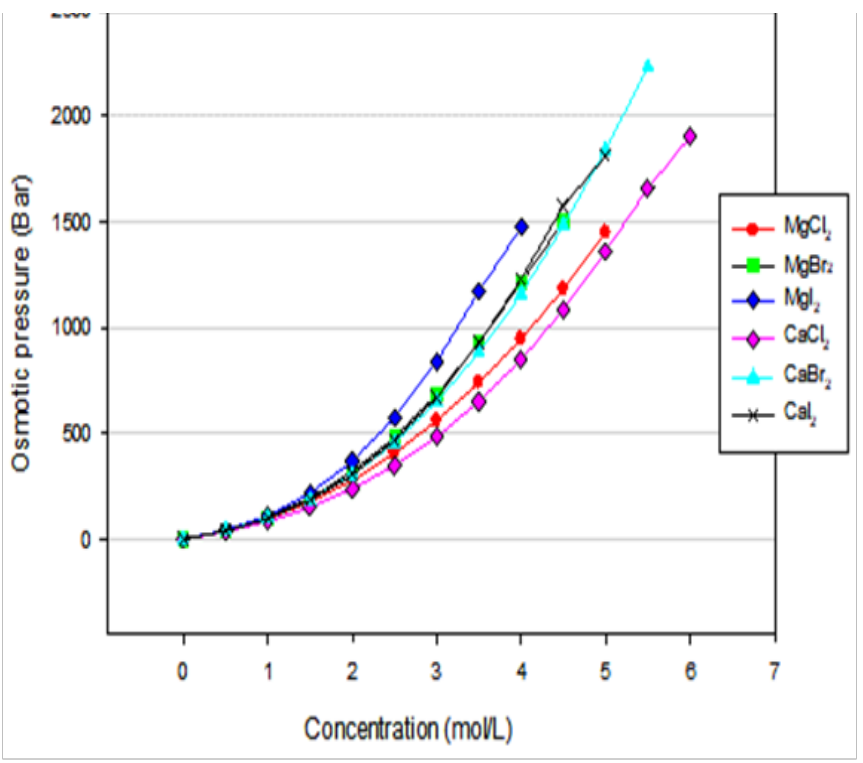

Figure 6 High osmotic pressure salts as calculated by OLI Analyzer.

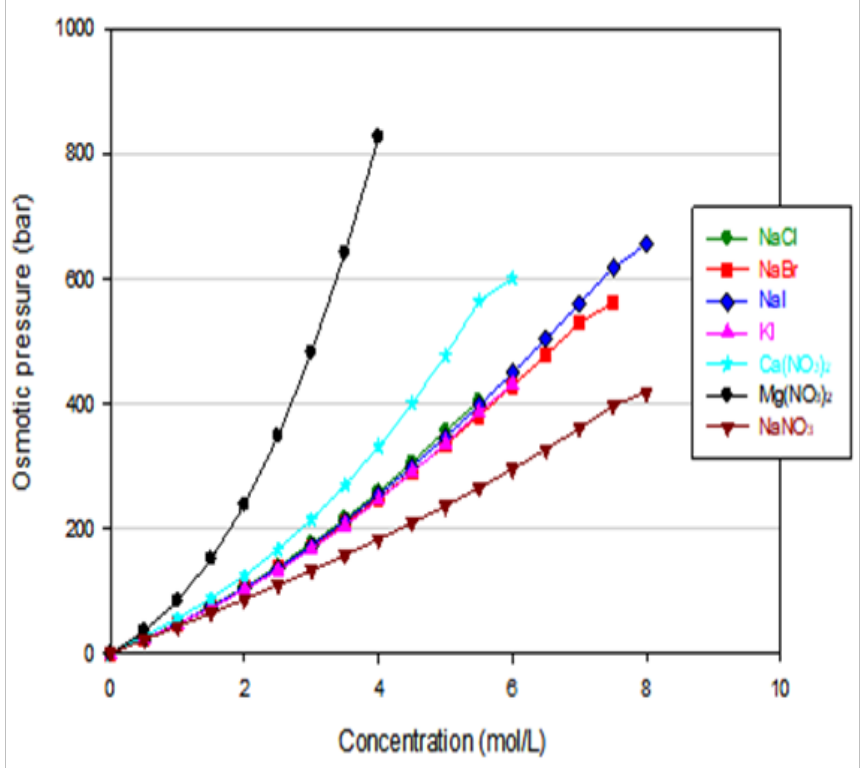

Figure 7 Moderate osmotic pressure salts as calculated by OLI Analyzer.

Firstly the calculated osmotic pressure of various salts at $25^{\circ} \mathrm{C}$ and $1 \mathrm{~atm}$ were compared. The salts are divided into three groups according to the difference of maximum osmotic pressure, which are the high osmotic pressure group (some divalent salts), the moderate osmotic pressure group (some monovalent salts) and low osmotic pressure groups (some sulfate salts), as shown in Figures 6-8. For all salts, the osmotic pressures are given as function of concentration $(\mathrm{mol} / \mathrm{L})$. In the high osmotic pressure group, the maximum osmotic pressure is in the range of 1200 to 2300 bar. These salts are magnesium halogens or calcium halogens. They have relatively large molecular size, but become acidic in the aqueous solution, which may cause serious corrosion to well pipes. In the moderate osmotic pressure group, the salts are sodium halogens, potassium iodide and some nitrites. These salts have medium osmotic pressure in the range of 400 to 900 bar. Some of these salts are cheap and not aggressive to the environment, for example sodium chloride. The low osmotic pressure group includes some sulfate salts and potassium nitrite, which have the maximum osmotic pressure in the range of 30 to 120 bar.

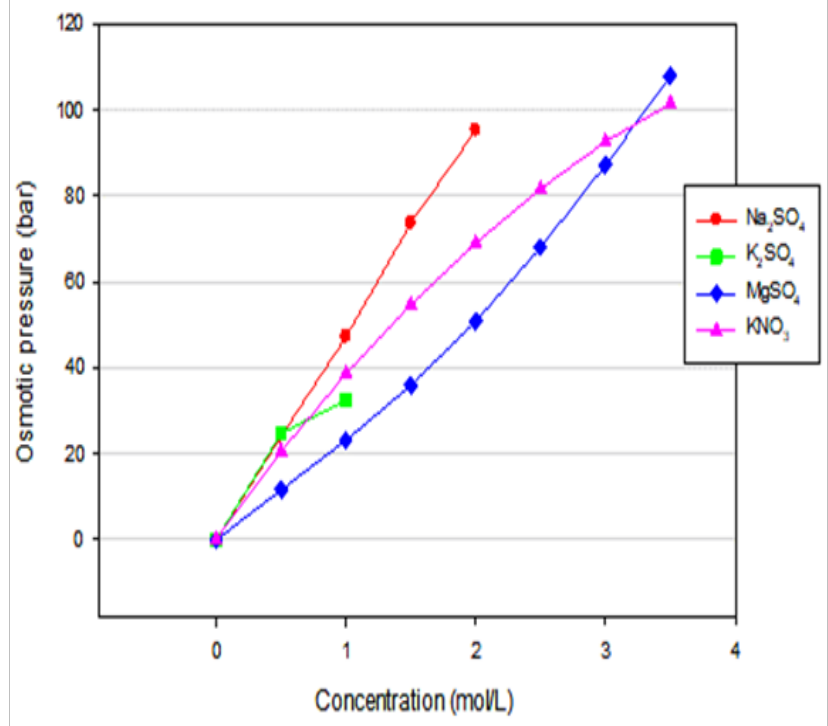

Figure 8 Low osmotic pressure salts as calculated by OLI Analyzer.

The salt solution in OMPA can be a single component or a mixture of a couple of components to provide the desired osmotic pressure. One salt was selected as candidate salt from each group for further investigations using the OLI Analyzer. These salts were: magnesium chloride $\left(\mathrm{MgCl}_{2}\right)$, sodium chloride $(\mathrm{NaCl})$ and sodium sulfate $\left(\mathrm{Na}_{2} \mathrm{SO}_{4}\right)$, since these salts are relatively cheap compared to the other salts in their groups. The temperature down in the well will be high, thus the changes of osmotic pressure with temperature of the three salts at almost saturated solutions were investigated, and the results are shown in Figure $9 \&$ Figure 10. The osmotic pressure of $4.5 \mathrm{M} \mathrm{MgCl}_{2}$ solution increases with increasing temperature from $20^{\circ} \mathrm{C}$ to $140^{\circ} \mathrm{C}$ at $179 \mathrm{bar}$, but there is an abrupt drop point at $150^{\circ} \mathrm{C}$. For $6 \mathrm{M} \mathrm{NaCl}$ solution, the osmotic pressure increases steadily with temperature from $20^{\circ} \mathrm{C}$ to $200^{\circ} \mathrm{C}$. The plot of the osmotic pressure of a $2 \mathrm{M} \mathrm{Na}_{2} \mathrm{SO}_{4}$ solution with temperature shows a different tendency (Figure 10). The osmotic pressure increases abruptly from $20^{\circ} \mathrm{C}$ to $30^{\circ} \mathrm{C}$, then increases slowly and reaches a maximum osmotic pressure at $160^{\circ} \mathrm{C}$. The difference of calculated osmotic pressure change with temperature of the three salts may be ascribed to the different change of water activities with temperature (Equation 2), which is caused by the intermolecular interaction of the solute with water molecules. For example; sulfate anions in water can form hydrate clusters by the formation of a hydrogen bond with water. ${ }^{23,24}$ leading to a relative lower water activity, hence the calculated osmotic pressure of sulfate salts is low. 
The calculated osmotic pressures for the three salts at $165^{\circ} \mathrm{C}$ and 179 bar are shown in Figure 11, which is at the design basis well conditions used in this study. The salt solution to be used in OMPA should be saturated, thus it will be designed with a salt reservoir. The concentration of the saturated solution is strongly dependent on temperature. Saturation concentration of $\mathrm{MgCl}_{2}$ solution increases from $4.5 \mathrm{M}$ at $20^{\circ} \mathrm{C}$ to $7.5 \mathrm{M}$ at $165^{\circ} \mathrm{C}$ and the maximum osmotic pressure increases to $3569 \mathrm{bar}$, while the concentration of saturated $\mathrm{NaCl}$ increases to around $7.5 \mathrm{M}$ with an increased osmotic pressure to $\sim 800$ bar. Finally, the saturation concentration of $\mathrm{Na}_{2} \mathrm{SO}_{4}$ solution increases only to about $2.5 \mathrm{M}$ giving an osmotic pressure of less than 200 bar by increasing the temperature from $20^{\circ} \mathrm{C}$ to $165^{\circ} \mathrm{C}$.

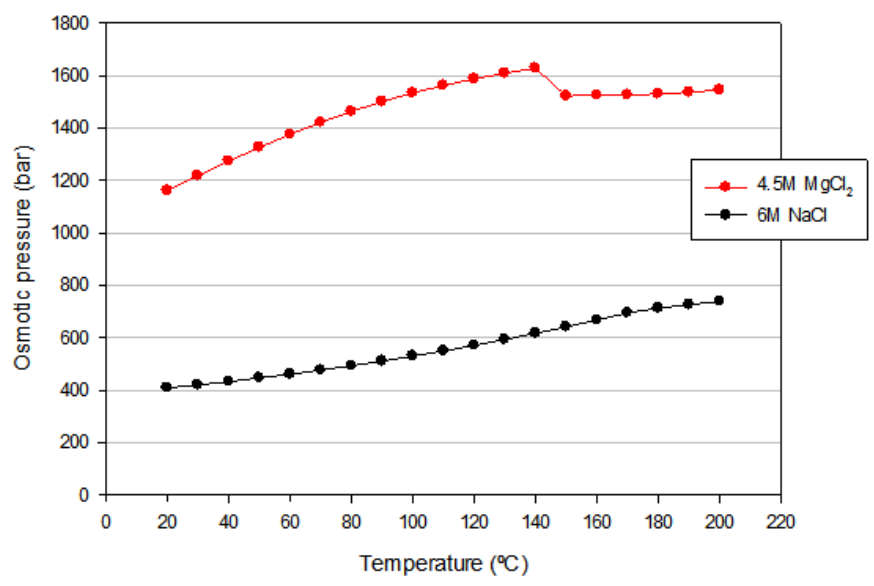

Figure 9 The change of osmotic pressure with temperature at 179 bar for $4.5 \mathrm{M} \mathrm{MgCl}_{2}$ and $6 \mathrm{M} \mathrm{NaCl}$, as calculated by OLI Analyzer.

The osmotic pressure of salt solutions varies very little with pressure in the range of $20 \mathrm{bar}$ to $200 \mathrm{bar}$ at $165^{\circ} \mathrm{C}$. This is because the water activities of the salt solutions change very little by varying pressure in the range of 20 bar to 200 bar at a constant temperature, as also predicted by the software OLI Analysis, however not shown here.

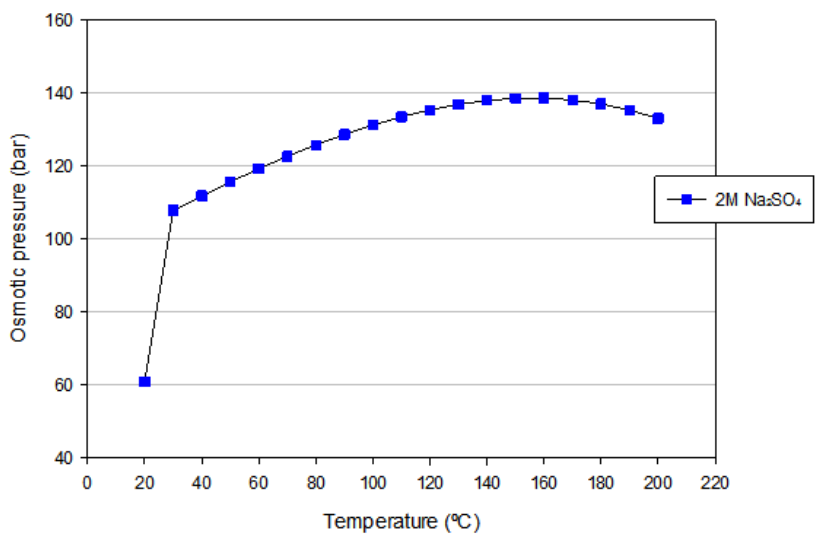

Figure 10 The change of osmotic pressure of $2 \mathrm{M} \mathrm{Na}_{2} \mathrm{SO}_{4}$ with temperature at 179 bar, as calculated by OLI Analyzer.

The selection of salt type and compositions for OMPA depends on membrane performance and expected OMPA response time. It thus seems quite obvious that $\mathrm{MgCl}_{2}$ will not be a good choice at the given well conditions. If the membrane has relative high-water flux, and along response time is expected for the OMPA to close down the well, then the drawing salt solution might be chosen from salts with low osmotic pressure, such as a mixture of $\mathrm{Na}_{2} \mathrm{SO}_{4}$ with $\mathrm{NaCl}$. In lab, however, where operating conditions are much lower pressure ( 1 bar) and temperatures of $23^{\circ} \mathrm{C}$ and $40^{\circ} \mathrm{C}$, it is useful to choose a salt like $\mathrm{MgCl}_{2}$ which will produce a high osmotic pressure also at the experimental lab conditions. $\mathrm{MgCL}_{2}$ was thus chosen for the benchscale experiments reported here to mimic osmotic pressure at well conditions.

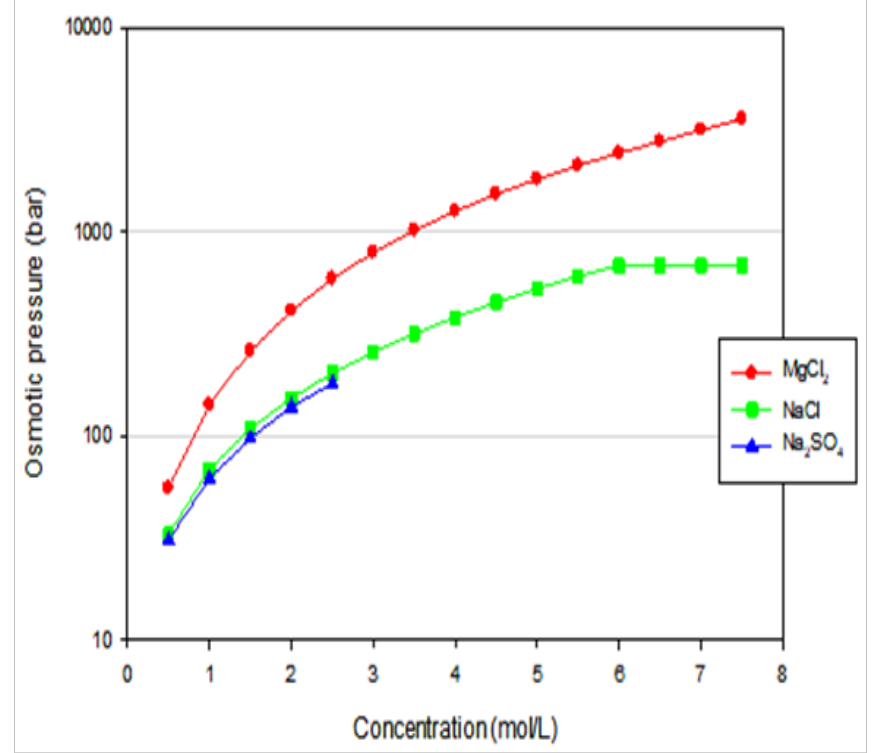

Figure II Osmotic pressure of different concentrations of salts at $165^{\circ} \mathrm{C}$, I79bar, as calculated by OLI Analyzer.

\section{Investigating membrane material properties for OMPA}

The idea of using an osmotic membrane in an OMPA valve for shutting off a water producing branch of an oil/gas well is a novel application, and there is no information to be found in open literature. The experimental investigations hence started out by choosing a commercial FO membrane to study the relationship between membrane water flux and response time, and the influence of some process parameters. It was, however, very clear that this FO membrane would not be a suitable material for the given process conditions in the well - hence it was studied as a reference case. The commercial FO membrane (delivered by HTI) is a flat-sheet cellulose triacetate (CTA) membrane. The membrane is embedded in a polyester mesh, which is different from RO membranes consisting of a thin active layer and a thick porous support layer. ${ }^{16}$ The HTI-membrane is thus more like a symmetric membrane without a porous support layer and will to a certain extent be reducing the problem of internal concentration polarization which is often a problem for FO membranes. Reduced concentration polarization will also be highly important for an OMPA membrane; hence a symmetric membrane material design is investigated for the new OMPA. The available commercial CTA membrane is not designed for high temperature application. The important investigation using the HTI FO membrane was thus done to indicate what a suitable water flux of the OMPA membrane should be. The membrane was tested at both FO and PRO process conditions.

Based on these findings, two other materials suitable for the harsh process conditions down in the well were chosen for further 
studies. These materials were polybenzimidazole $(\mathrm{PBI})$ prepared with varying amounts of $\mathrm{LiCl}$ and a novel fluoropolymer, here indicated as fluoro-X. PBI is a thermally stable polymer up to around $400^{\circ} \mathrm{C}$, and the chosen fluoro- $\mathrm{X}$ up to around $500^{\circ} \mathrm{C}$. These materials are still under development. Some initial results are included in 5.1.1.

\section{Results and discussion}

\section{Bench-scale FO system and PRO system}

The bench-scale FO system used is a standard system, described elsewhere. ${ }^{25,26}$ A schematic drawing is shown in Figure 12. The benchscale PRO system is slightly modified compared to the FO system, ${ }^{27}$ where a ball valve and a pressure transmitter are placed on the side of draw solution. After the feed solution (here distilled water) and draw solution (here $1 \mathrm{M} \mathrm{MgCl}_{2}$ ) were circulated at steady state, the valve in the side of draw solution was closed, and the increasing pressure in the draw solution was logged into a computer. The increased pressure is the osmotic pressure difference of the two solutions, called produced pressure here. The change in conductivity of feed solution (water) was measured by a conductivity meter, which indicated the amount of salt diffusing from draw solution to feed water. The change in weight of feed water was measured by a scale, which represented the amount of water permeating through the membrane into the draw solution. A porous steel plate was placed on the feed side as support for the membrane. The membrane was placed on the porous steel plate with the membrane facing to the draw solution. (For a better understanding of the system, see section 3.1 Osmotic Membrane Theory - General part)

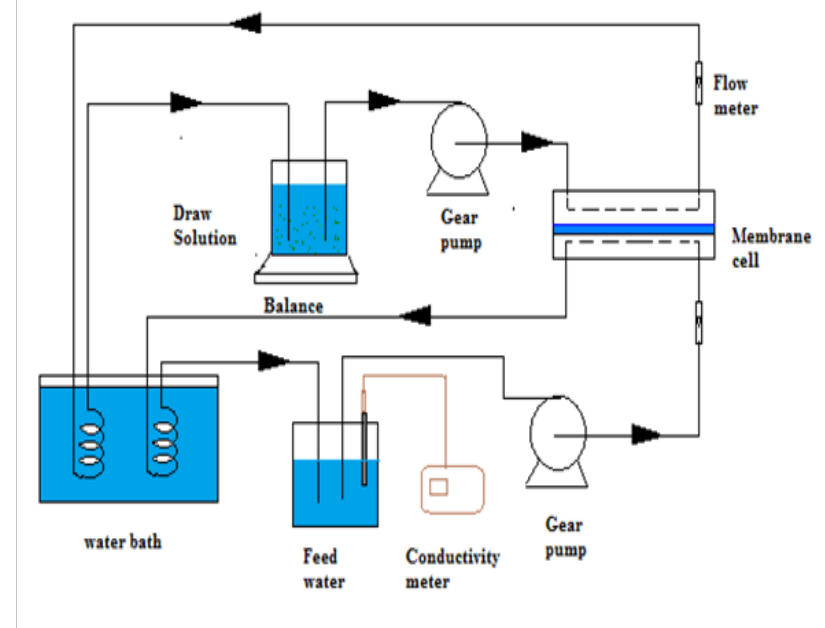

Figure 12 The scheme of the bench-scale FO system.

The osmotic pressure produced by the FO membranes: The commercial CTA membrane (supplied by HTI) was firstly tested in FO process mode. Distilled water was used as feed solution and $1 \mathrm{M}$ $\mathrm{MgCl}_{2}$ was used as draw solution. As already discussed in section 4.1 and calculated by the OLI Analyzer, the draw solution in the OMPA will need to be saturated at the given well conditions, which will eliminate $\mathrm{MgCl}_{2}$ as a choice for application in a real well. However, for the controlled bench scale experiments, a low concentration (1M) $\mathrm{MgCl}_{2}$ was used in order to provide an acceptable high osmotic pressure which could, to a certain extent, be compared to a saturated $\mathrm{NaCl}$ solution at same temperature (Figure 6) (Figure 9). The experiment was performed at three different temperatures, while the flow rates of feed solution and draw solution were circulated at
$500 \mathrm{~mL} /$ minute. The calculated membrane water flux and reverse salt flux are shown in Table 1. The uncertainties in the numbers are about $5 \%$. The membrane water flux and reverse salt flux both increased with temperature as expected. The commercial FO membrane used in the experiments is ultrathin, and has a relatively high flux, while the OMPA membrane will need to be thicker and probably reinforced if a symmetric design is chosen. The salt flux needs to be much lower in OMPA membrane. Based on the indications obtained with this commercial CTA membrane, the two materials which were chosen to be suitable for the OMPA membrane under harsh well conditions, were tested. Initial results for the two chosen materials PBI-LiCl and a proprietary fluoropolymer (fluoro-X) are given in Table 2, using same draw solution and flow rates as for the CTA-membrane. Uncertainties in the numbers are about $8 \%$. The results are giving an indication of the interesting range for the water flux and reverse salt flux compared to the CTA commercial membrane. Even lower salt flux will be aimed for in the final design. The membranes tested are symmetric and resting on a porous steel support with pore size approximately 200 $\mu \mathrm{m}$.

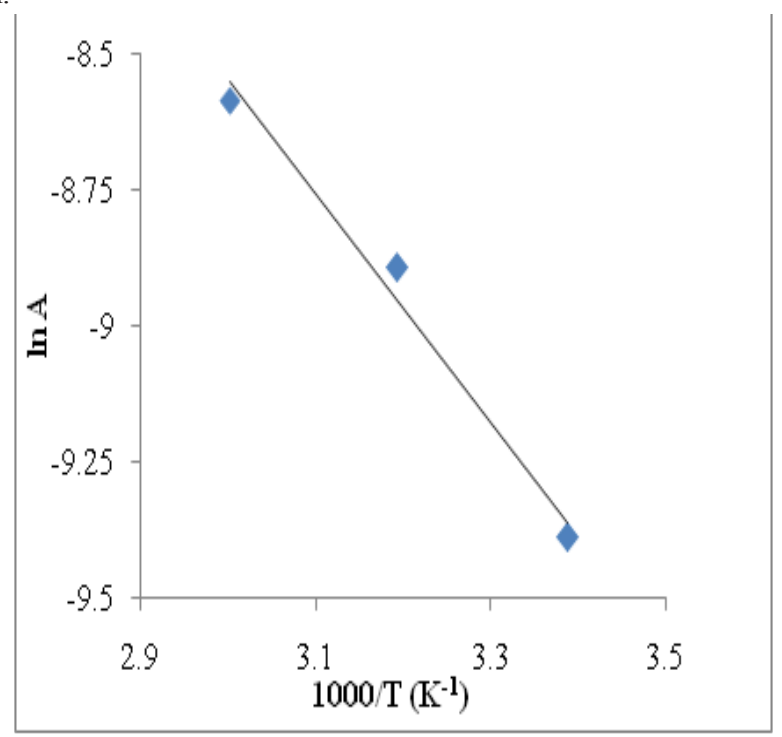

Figure 13 Arrhenius plot from $\ln A$ and 1000/T.

Table I CTA commercial FO membrane; water flux and reverse salt flux.

\begin{tabular}{llll}
\hline $\begin{array}{l}\text { Temperature } \\
\left({ }^{\circ} \mathrm{C}\right)\end{array}$ & $\begin{array}{l}\text { Calculated osmotic } \\
\text { pressure (bar) }\end{array}$ & $\begin{array}{l}\text { Water flux } \\
\left(\mathbf{L} / \mathbf{m}^{2} \mathbf{~ h r}\right)\end{array}$ & $\begin{array}{l}\text { Reverse salt } \\
\text { flux }(\mathbf{m m o l} / \\
\left.\mathbf{~}^{2} \mathbf{~ h r}\right)\end{array}$ \\
\hline 22 & 95.8 & 8.0 & 7.9 \\
40 & 101.3 & 13.9 & 12.4 \\
60 & 107.5 & 20.1 & 16.9 \\
\hline
\end{tabular}

Referring to Table 1 and equation 1 , the water permeability constant $A$ at the three temperatures can be calculated. $A$ increases with temperature because the driving force increases with temperature. Applying Arrhenius equation to experimental data, activation energy of water permeation, $\mathrm{E}_{p}$ was calculated as follows:

$$
A=A_{0 e}{ }^{-E p / R T} \ldots \ldots \text { (Eq. 5) }
$$

Where $A$ represents water permeability constant, $A_{0}$ is pre exponential factor, $\mathrm{E}_{p}$ is activation energy of water permeation.

By plotting $\ln$ A versus 1/T, activation energy is calculated from the slope of the linear least square fit (Figure 13), is found to be 
$17.35 \mathrm{~kJ} / \mathrm{mol}$. $\mathrm{A}_{0}$ is $0.10 \mathrm{~m}^{3} /\left(\mathrm{m}^{2} \mathrm{hr}\right.$ bar). By using Arrhenius equation (Eq.5), the water permeability constant $\mathrm{A}$ at $165^{\circ} \mathrm{C}$ is thus predicted to be $8.65 \mathrm{E}-4 \mathrm{~m}^{3} /\left(\mathrm{m}^{2} \mathrm{hr}\right.$ bar $)$, with an estimated error of $7 \%$. The water flux at $165^{\circ} \mathrm{C}$ would be $122.0 \mathrm{~L} / \mathrm{m}^{2} \mathrm{hr}$ (Eq.1), by using $1 \mathrm{M} \mathrm{MgCl}_{2}$ solution with osmotic pressure $141.1 \mathrm{bar}$ at $165^{\circ} \mathrm{C}$ (ref. Figure 11). It is expected that the water flux will increase comparably for a saturated $\mathrm{NaCl}$ solution at $165^{\circ} \mathrm{C}$. From the calculated expected water flux, the thickness of the membrane can be adjusted and response time for OMPA calculated.

\section{Predicting response time for OMPA}

To predict the response time can be challenging, however, a simplified method is used here. As an example: If we assume a 0.2 meter wide and 0.5 meter long membrane in each OMPA, the available membrane area is $0.1 \mathrm{~m}^{2}$. Assuming a $2 \mathrm{~cm}$ free space above the membrane, gives the volume in the osmotic chamber (draw solution) of $0.002 \mathrm{~m}^{3}$, and the free space for the OMPA to move can be set to be the same. The draw solution is assumed to be fully de-gassed, thus the draw solution can hardly be compressed. When produced water starts to intrude into the oil fluid, the water will permeate into the draw solution across the membrane. The pressure in the draw solution will increase. At the beginning the draw solution is assumed to be at the same pressure as that of the oil fluid. When the water starts permeating into the draw solution, OMPA will start to respond. The volume available for OMPA from the starting response to the fully closed, is here assumed to be $0.002 \mathrm{~m}^{3}$ or 2 litre (see above). The water flux is assumed to be constant for a given system, depending on the membrane material and thickness, and as already discussed, the choice of draw solution. A rough calculation of the response time can then be performed using Eq.6. Table 3 is showing response time for different membrane water flux.

$$
T R=\frac{V}{J_{w} A r 24} \ldots \cdots \cdots(\text { Eq. } 6)
$$

Where $T_{R}$ (days) is the response time, $V(L)$ is the volume for OMPA from the starting response to the fully closed, $J_{w}\left(\mathrm{~L} / \mathrm{m}^{2} \mathrm{hr}\right)$ is membrane water flux, $\mathrm{A}_{\mathrm{r}}\left(\mathrm{m}^{2}\right)$ is the membrane area. A desired response time may be in the range of 3 to 10 days for the practical requirement. From Table 3, the expected membrane water flux should then be in the range of 0.08 to $0.3 \mathrm{~L} / \mathrm{m}^{2} \mathrm{hr}$ at the well conditions, hence according to Table 1 and equation 6 the membrane water flux at room temperature should then be much less than those obtained in the experiments with the commercial CTA membrane. The initial reported results for the PBI and fluoro- $\mathrm{X}$ are still too high as can be seen in Table 2. The assumption in these calculations was that the water flux (A) is constant, however this may have to be modified in the real case when concentration polarization is taken into account. Table $2 \mathrm{PBI}-\mathrm{LiCl}$ and a fluoropolymer; water flux and reverse salt flux

\begin{tabular}{llll}
\hline $\begin{array}{l}\text { Temperature } \\
\left({ }^{\circ} \mathbf{C}\right)\end{array}$ & $\begin{array}{l}\text { Membrane } \\
\text { thickness } \\
(\boldsymbol{\mu m})\end{array}$ & $\begin{array}{l}\text { Water flux }(\mathrm{L} / \\
\left.\mathbf{m}^{2} \mathbf{~ h r}\right)\end{array}$ & $\begin{array}{l}\text { Reverse salt } \\
\text { flux }(\mathbf{m m o l} / \\
\left.\mathbf{m}^{\mathbf{2}} \mathbf{~ h r}\right)\end{array}$ \\
\hline 22 & $55(\mathrm{PBI})$ & 0.3 & $\mathrm{I} .2$ \\
22 & 35 (fluoro-X) & 0.3 & $\mathrm{I}$ \\
\hline
\end{tabular}

The calculation of needed response time is setting the basis for the design of the OMPA as well as developing the membrane material with the final performance properties needed. The two materials referred to in Table 2 are currently being optimized and tested at relevant pressures and temperatures for the given well conditions, using $\mathrm{NaCl}$ as the draw solution.

Table 3 Membrane water flux corresponding to response time

\begin{tabular}{lllllllll}
\hline$J_{w}\left(L / m^{2} h r\right)$ & 0.01 & 0.05 & 0.08 & 0.1 & 0.3 & 0.5 & 1 & 5 \\
\hline $\mathrm{T}_{\mathrm{R}}$ (days) & 83.3 & 16.6 & 10.4 & 8.3 & 2.8 & 1.7 & 0.8 & 0.2 \\
\hline
\end{tabular}

\section{Conclusion}

The application of using an osmotic membrane in the pressure actuator for detecting and choking produced water intrusion in an oil/ gas well is being investigated as a new application area for a tailored forward osmotic membrane. If successful, this application may have a huge potential for increased value creation in enhanced oil and gas recovery. The membrane for the OMPA valve must be highly thermos table and chemical resistant to survive the harsh environment in the wells. The material for the membrane are chosen from thermally and chemically stable polymeric materials, in the current work a polybenzimidazole and a fluoropolymer are investigated, and promising, initial results obtained. As documented in the above discussion, the membrane for OMPA must have very low water flux and reverse salt flux - in the current investigations we have chosen to compare two membrane materials relative to the commercial HTI FO membrane and use this CTA membrane as base case. The predicted membrane water flux at 179 bars and $165^{\circ} \mathrm{C}$ should be in the range of 0.08 to $0.3 \mathrm{~L} / \mathrm{m}^{2} \mathrm{hr}$, given the response time is set to around one week.

\section{Acknowledgements}

The authors wish to thank Statoil ASA and the Norwegian Research Council (through the grant \#217211) for financial support of this project. We would also like to acknowledge HTI Hydration for providing the CTA forward osmotic membranes, likewise Dr. M. Zolotukhin at Universidad Nacional Autonoma de Mexico for providing the fluoropolymers. Dr. T-J. Kim and Dr. M. Sandru at Sintef M\&C are acknowledged for assistance of building the experimental set-up and running the experiments, likewise Dr. G. Barbieri at ITM-CNR is acknowledged for constructive contributions both in discussions and testing.

\section{Conflict of interest}

The author declares that there is no conflict of interest.

\section{References}

1. Joshi SD. Horizontal Well Technology. Oklahoma: PennWell;1991:1-29.

2. Trevor Burgess, PVd Slijke. Horizontal drilling comes of age. Oilfield Review. 1990;2:22-33.

3. Ahmadun FR, Pendashteh A, Abdullah LC. Review of technologies for oil and gas produced water treatment. J Hazard Mater. 2009;170(2-3):530 551.

4. Alley B, Beebe A, Rodgers J, et al. Chemical and physical characterization of produced waters from conventional and unconventional fossil fuel resources. Chemosphere. 2011;85(1):74-82.

5. Cakmakci M, Kayaalp N, Koyuncu I. Desalination of produced water from oil production fields by membrane processes. Desalination. 2008;222(13):176-186.

6. Ekins P, Vanner R, Firebrace J. Zero emissions of oil in water from offshore oil and gas installations: economic and environmental implications. $J$ Clean Prod. 2007;15(13-14):1302-1315. 
7. Tellez GT, Nirmalakhandan N, Gardea-Torresdey JL. Performance evaluation of an activated sludge system for removing petroleum hydrocarbons from oilfield produced water. Adv Environ Res. 2002;6(4):455-470.

8. U.S. Environmental Protection Agency.

9. Ozgun H, Ersahin ME, Erdem S, et al. Effects of the pre-treatment alternatives on the treatment of oil-gas field produced water by nanofiltration and reverse osmosis membranes. $J$ Chem Technol Biot. 2013;88(8):1576-1583.

10. Mondal S, Wickramasinghe SR. Produced water treatment by nanofiltration and reverse osmosis membranes. J Membrane Sci. 2008;322(1):162-170.

11. Nyhavn F. US 2013/0245948, Extracting downhole flow profiles from tracer flowback transients.

12. Woiceshyn GE, F Nyhavn. US 2013/0112400, wellbore fluid treatment and method.

13. Nyhavn F. EP 2633152B1, Method for using tracer flowback for estimating influx volumes of fluids from different influx zones.

14. Aakre A. US 7,819,196, Method for operating actuator and an actuator device for use in drainage pipe used for producting oil and/or gas.

15. Mulder J. Basic Principles of Membrane Technology. Kluwer Academic Publishers. 2003;282-305.

16. Cath TY, Childress AE, Elimelech M, 2006) Forward osmosis: Principles, applications, and recent developments. J Membrane Sci. 2006;281(12):70-87.

17. Chung TS, Zhang S, Wang KY, et al. Forward osmosis processes: Yesterday, today and tomorrow. Desalination. 2012;287:78-81.
18. Qin JJ, Lay WCL, Kekre KA. Recent developments and future challenges of forward osmosis for desalination: a review. Desalin Water Treat. 2012;39(1-2):123-136.

19. Zhao SF, Zou L, Tang CYY, et al. (2012) Recent developments in forward osmosis: Opportunities and challenges. J Membrane Sci. 2012;396:1-21.

20. Lee Kp, Arnot TC, Mattia D. A review of reverse osmosis membrane materials for desalination-Development to date and future potential. J Membrane Sci. 2011;370(1-2):1-22.

21. Achilli A, Cath TY, Childress AE. Power generation with pressure retarded osmosis: An experimental and theoretical investigation. J Membrane Sci. 2009;343(1-2):42-52.

22. Oli System.

23. Wang XB, Yang X, Nicholas JB, et al. Bulk-like features in the photoemission spectra of hydrated doubly charged anion clusters. Science. 2001;294(5545):1322-1325.

24. Bush MF, Saykally RJ, Williams ER. Evidence for water rings in the hexahydrated sulfate dianion from IR spectroscopy. J Am Chem Soc, 2007;129(8):2220-2221.

25. McCutcheon JR, Elimelech M. Influence of concentrative and dilutive internal concentration polarization on flux behavior in forward osmosis. $J$ Membrane Sci. 2006;284(1-2):237-247.

26. Yip NY, Tiraferri A, Phillip WA, et al. High Performance ThinFilm Composite Forward Osmosis Membrane. Environ Sci Technol. 2010;44(10):3812-3818.

27. Chou SR, Wang R, Shi L, et al. Thin-film composite hollow fiber membranes for pressure retarded osmosis (PRO) process with high power density. J Membrane Sci. 2012;389:25-33. 